East African Medical Journal Vol. 77 No. 12 December 2000

SEXUALLY TRANSMITTED DISEASES AT QUEEN ELIZABETH CENTRAL HOSPITAL, BLANTYRE, MALAWI

O. O. Komolafe, DVM, MSc, PhD, J. Nkumba, M. Makoka, A. Makhalira and P. Bonongwe, Department of Microbiology, College of Medicine, University of Malawi, P/Bag 360, Chichiri, Blantyre 3, Malawi.

\title{
SEXUALLY TRANSMITTED DISEASES AT QUEEN ELIZABETH CENTRAL HOSPITAL, BLANTYRE, MALAWI
}

\author{
O. O. KOMOLAFE, J. NKUMBA, M. MAKOKA, A. MAKHALIRA and P. BONONGWE
}

\begin{abstract}
Objectives: To re-assess attendance at the sexually transmitted diseases (STDs) clinic in relation to age, sex and seasonal variation over a three-year period, and to determine the pattern of STD syndromes presenting at the STDs clinic, Queen Elizabeth Central Hospital, Blantyre, Malawi.

Design: A retrospective study.

Setting: STDs clinic, Queen Elizabeth Central Hospital (QECH), Blantyre, Malawi.

Results: The study findings indicate that of the $\mathbf{5 0 , 5 2 4}$ attendees, $\mathbf{5 2 . 7 2 \%}$ and $\mathbf{4 7 . 2 8 \%}$ were males and females respectively. Over the period there was a significant $(30.7 \%)$ increase in the number of attendees from 14,622 (28.94\%) in 1996 and $16,794(33.24 \%)$ in 1997 to 19,008 $(37.82 \%)$ in $\mathbf{1 9 9 8}$, a trend that was also observed among the sexes. The age range was between 11 and 72 years. More than half $(53.55 \%)$ of the patients were within 21 to 30 years age range while a total of $48,054(95.11 \%)$ were below 50 years. The most frequently presented STDs syndromes among the 21- 30 year age group were genital ulcer disease (GUD) (40.86\%), genitourinary symptoms high risk (GUS - HR) $(\mathbf{2 0 . 4 6 \%})$, urethral discharge (UD) $\mathbf{( 1 5 . 6 5 \% )}$ and pelvic inflammatory diseases (PID) $(13.37 \%)$. The four constituted $90.34 \%$ of all case presentations. Balanitis (BA) was the least common at $0.32 \%$ or 86 cases in three years. While the incidence of genitourinary symptoms low risk (GUS - LR) decreased over the years and no clear pattern could be established with (GUS - HR), acute scrotal swelling/pain (SS), and BA, numerical increase in the presentation of UD, PID and enlarged inguinal lymph nodes (BU) was observed. However, the phenomenal increase in the prevalence of STDs particularly GUD rising from $2,988(37.70 \%)$ in 1996 and 3,674 $(40.27 \%)$ in 1997 to $4,392(43.88 \%)$ in 1998 respectively was noted with concern. There seemed to be a link between seasonal variation and attendance at the STD clinic as more cases presented between March and May peaking in April of each year while December period recorded the least attendance.

Conclusion: Attendance rate at the STDs clinic, Queen Elizabeth Central Hospital, Blantyre, is still on the increase in spite of the various STDs/HIV/AIDS awareness campaign programmes.
\end{abstract}

\section{INTRODUCTION}

Sexually transmitted diseases (STDs) are among the most frequently occurring infections worldwide. It has also been estimated that among adults aged 15-49, there were 332 million cases of STDs worldwide and over $76 \%$ of these infections occurred in the developing world(1). In Malawi, STDs other than HIV are widespread and account for a significant burden on the country's health services(2). Taken as a group, STDs are the fourth most common reason for consultation in the adult outpatient departments (OPD) nationwide(3).

Syndromic management of STD cases was introduced in Malawi in 1992 and by 1995 a 25\% increase in clinic attendance over the 1991 figures was observed in a 1991 - 1995 retrospective study on STD clinic records kept at the Queen Elizabeth Central Hospital, Blantyre(4). This situation was of considerable concern to health care delivery personnel from the point of view of spread and control of STDs, including HIV.

The present retrospective study was conducted as a follow up to that study(4) to reassess attendance at the STDs clinic in relation to age, sex, and seasonal variation over a three-year (1996 - 1998) period and also to determine the pattern of STDs syndromic distribution.

\section{MATERIAL AND METHODS}

Case records of patients who attended the STDs clinic at the QECH, Blantyre from January 1996 to December 1998 were retrieved and studied. Analyses were made based on sex, age and the pattern of STDs syndromic distribution. Total monthly attendance figures were compiled over the three-year period to check if there was any seasonal variation in clinic attendance. Only patients who registered as new cases were considered in this analysis. 


\section{RESULTS}

Distribution by sex and age: A total of 50,524 patients which included 26,634 (52.72\%) males and $23,890(47.28 \%)$ females presented to the STDs clinic within the study period. A significant increase in the number of attendees was observed rising from 14, 622 (28.94\%) in 1996 and 16, $794(33.24 \%)$ in 1997 to 19,008 $(37.82 \%)$ in 1998 . The numbers of male patients were consistently higher than those of females (Table 1) over the study period.

Table 1

Total number and sex distribution of outpatients at the STDs clinic

\begin{tabular}{lrrrrr}
\hline Year & \multicolumn{2}{c}{ Sex } & Total & $\begin{array}{r}\text { Case load/ } \\
\text { working } \\
\text { day }\end{array}$ \\
\cline { 2 - 3 } & Male & Female & & 56 \\
1996 & 7731 & 6891 & $14622(28.94 \%)$ & 56 \\
1997 & 8874 & 7620 & $16494(33.24 \%)$ & 63 \\
1998 & 10029 & 9079 & $19108(37.82 \%)$ & 74
\end{tabular}

Total $26634(52.73 \%) \quad 23890(27.28 \%) \quad 50524(100 \%)$ three-year study period, the difference however was not statistically significant. The number of patients below the age of 50 was 48,054 or $95.11 \%$ of the overall total.

Table 2

Age distribution of STD clinic attenders

\begin{tabular}{lrr}
\hline Age range (yrs) & No. of patients & $\%$ total \\
\hline $11-20$ & 8,554 & 16.93 \\
$21-30$ & 27,056 & 53.55 \\
$31-40$ & 8,897 & 17.61 \\
$41-50$ & 3.547 & 7.02 \\
$51-60$ & 2,167 & 4.29 \\
Above 60 & 303 & 0.60 \\
\hline Total & & 100.00 \\
\hline
\end{tabular}

Pattern of STD syndromic distribution: The 21-30 years age group which comprised more than half $(53.55 \%)$ of the total number of STD outpatients was analysed to establish the pattern of syndromic distribution within the group (Table 3 ).

Table 3

Pattern of STDs syndromic distribution among 21-30 years age group attending clinic

\begin{tabular}{|c|c|c|c|c|c|}
\hline Syndrome & $1996(n=7,925)$ & $1997(\mathrm{n}=9,123)$ & $1998(n=10,008)$ & Total $(n=27,056)$ & $\%$ Total \\
\hline GUD & $2,988(37.70 \%)$ & $3,694(40.27 \%)$ & $4,392(43.88 \%)$ & 11,054 & 40.86 \\
\hline GUS (HR) & $1,672(21.10 \%)$ & $2,002(21.94 \%)$ & $1,861(18.60 \%)$ & 5,535 & 20.46 \\
\hline GUS (LR) & $256(3.23 \%)$ & $213(2.33 \%)$ & $138(1.38 \%)$ & 607 & 2.24 \\
\hline UD & $1,232(15.55 \%)$ & $1,474(16.16 \%)$ & $1,528(15.27 \%)$ & 4,234 & 15.65 \\
\hline PID & $1,144(14.44 \%)$ & $1,168(12.80 \%)$ & $1,306(13.05 \%)$ & 3,618 & 13.37 \\
\hline SS & $207(2.61 \%)$ & $200(2.19 \%)$ & $250(2.50 \%)$ & 657 & 2.43 \\
\hline $\mathrm{BU}$ & $176(2.22 \%)$ & $187(2.05 \%)$ & $194(1.94 \%)$ & 557 & 2.06 \\
\hline BA & $30(0.38 \%)$ & $23(0.25 \%)$ & $33(0.33 \%)$ & 86 & 0.32 \\
\hline Others & $220(2.77 \%)$ & $182(2.00 \%)$ & $305(3.05 \%)$ & 707 & 2.61 \\
\hline
\end{tabular}

Key: GUD = Genital ulcer disease; GUS (Hr)= Genito-urinary symptoms in women (high risk); GUS (lr)= Genito-urinary symptoms in women (low risk); UD = Urethral discharge; PID = Pelvic inflammatory disease; SS = Acute scrotal swelling/pain; BU = Enlarged inguinal lymph nodes BA = Balanitis; Others $=$ Genital warts, Candidiasis, Trichomoniasis, Bartholinitis abscess

The age distribution of STDs clinic outpatients between 1996 and 1998 is presented in Table 2. Clinic attenders between the 21-30 years age bracket accounted for 27,056 or $53.55 \%$ of the overall total with $31-40$ $(17.61 \%)$ and $11-20(16.93 \%)$ age groups coming a distant second and third respectively. Although more males $(13,744$ or $50.8 \%)$ than females $(13,312$ or $49.2 \%)$ within the 21-30 year age range attended the STDs clinic in the
By far the most prevalent syndromes over the study period were genital ulcer disease (GUD) (40.86\%), genito-urinary symptoms-high risk (GUS-HR) (20.46\%), urethral discharge (UD) (15.65\%) and pelvic inflammatory disease (PID) (13.37\%). All four together constituted $90.34 \%$ of all infections. Balanitis (BA) was the least common accounting for only 86 or $0.32 \%$ of all STDs cases in three years (Figure 1). 
Figure 1

A three-year pattern of STD syndromic distribution among the 21-30 years age groups

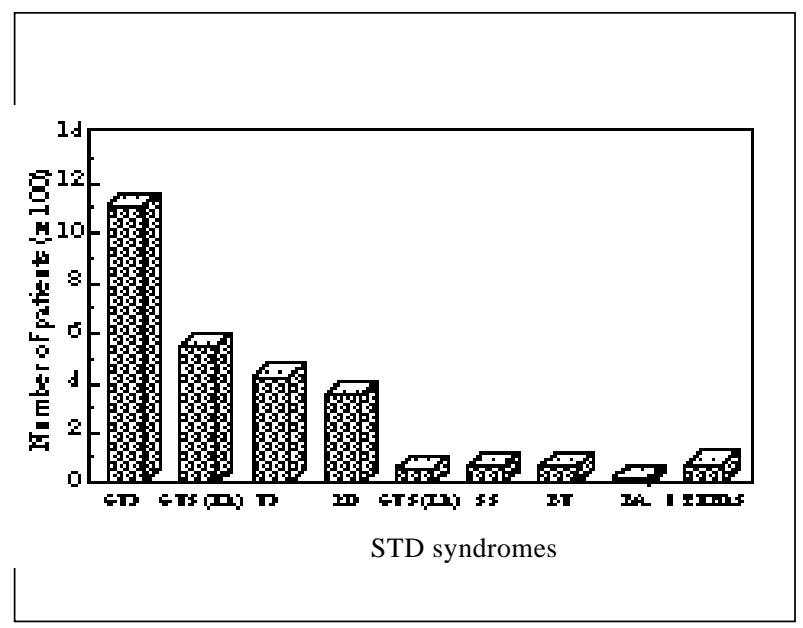

Figure 2

Relationship between seasonal variation and STD clinic attendance

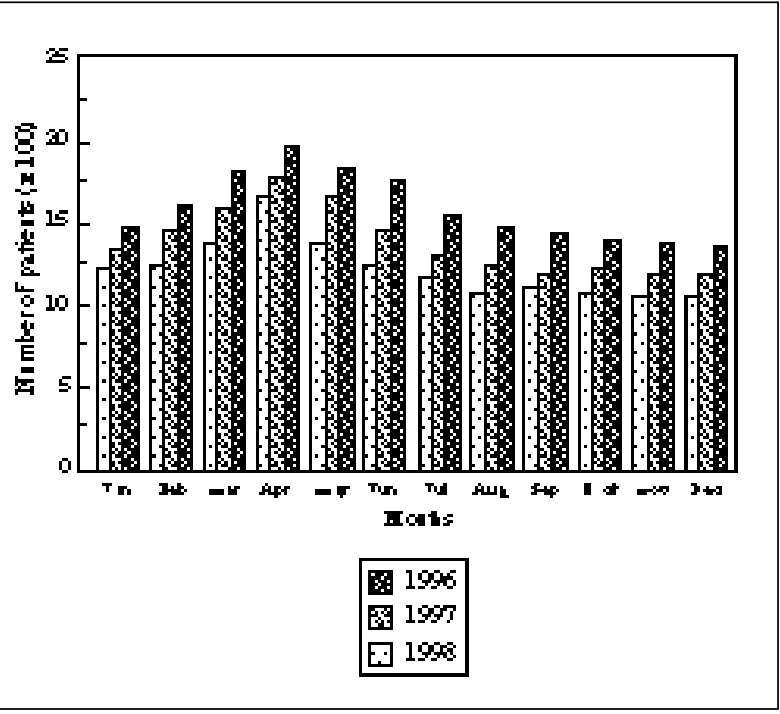

While GUS - low risk showed a marked decrease by $46 \%$, GUD cases increased by $47 \%$, UD (24\%) PID $(14.2 \%)$ and enlarged inguinal lymph nodes (BU) by $10.2 \%$ respectively. Although GUS-HR, acute scrotal swelling/pain (SS) and BA cases increased numerically, a clear prevalence pattern could not be established with these syndromes. Other STIs such as genital warts, candidiasis, trichomoniasis and bartholinitis abscess which accounted for 707 or $2.61 \%$ of all STD cases, also increased numerically (Table 3 ).

Effect of seasonal variation: Clinic attendance was highest between March and May peaking in April throughout the three -year study period (Figure 2), while the lowest figures were recorded in the month of December of each year.

\section{DISCUSSION}

Following the confirmation of the HIV/AIDS pandemic in Malawi in the mid 1980s(5), the awareness campaign against STDs became more pronounced as an indirect means of controlling the spread of HIV/AIDS in the country. One of the after-effects of that campaign was the increase in attendance at the STD clinic, QECH, Blantyre and more especially when STD syndromic case management became available in Malawi in 1992. By 1995 however, a 25\% increase over the 1991 attendance figures had been recorded(4) which the researchers attributed to a non-change in sexual behavioural pattern despite the HIV/AIDS awareness campaign. It also could have been due in part to free medication, counselling and the supply of free condoms that syndromic management offered.

The result of the present three-year (1996-98) retrospective study of STDs clinic attendance at QECH, Blantyre showed a sharp increase from 14,622 (1996) and 16,494 (1997) to 19,108 (1998) representing an increase of 4,486 or $30.7 \%$ over the study period. These figures translated to an average case load of 56, 63, 74 new cases respectively averaging 64 per working day over the threeyear period (Table 1). This, no doubt, is unacceptably high. However, the results confirmed the observation of earlier workers(4) who recorded a $25 \%$ increase in attendance over a five-year (1991-1995) study period. The fact that an increase of $30.7 \%$ over a three-year period (1996-1998) was observed in this study showed that the various HIV/AIDS awareness campaigns have had little or no effect on the sexual behaviour of Malawians as previously observed (6). Infact, with a population of about 10 million, Malawi is facing one of the worst HIV/ AIDS epidemic in the world(1).

The result also showed that there were more male attenders $(52.72 \%)$ than female counterparts $(47.28 \%)$. This observation was in sharp disagreement with the result of Kristernsen(3) who, in a pilot study on the prevalence of STDs presenting at the Kamuzu Central Hospital, Lilongwe, (Malawi), observed an attendance of $82.7 \%$ males compared to only $17.3 \%$ females. In addition to STDs awareness campaign already in progress, the invitation of sexual partners using partner notification cards in syndromic case management might have been responsible for the comparative number of male and female outpatients observed in this study. Furthermore, the asymptomatic carriage of STDs by women resulting in their reduced treatment-seeking behaviour(7) the fear of being stigmatised $(8,9)$ or having been misdiagnosed during health-seeking(10) could be some of the reasons why less women than men consistently presented to the STDs clinic.

As in previous studies(3), the highest proportion/ percentage of STDs clinic attenders in this study was in the 21-30 years age group (53.55\%), while a total of $95.11 \%$ were below 50 years (Table 2), an age range representing 
over $90 \%$ of the total active labour force in any country(11).

When patients in this group were analysed for the incidence of STDs by syndromic distribution, the diagnosis was dominated by a relatively large proportion of genital ulcer disease (Figure 1) increasing from $37.70 \%$ and $40.27 \%$ to $43.88 \%$ in 1996,1997 and 1998 respectively (Table 3). Furthermore, GUD in combination with GUS (HR), UD and PID accounted for $88.79 \%$ (1996) $91.17 \%$ (1997) and $90.80 \%$ (1998) averaging $90.25 \%$ of all STD presentations in those years. The continued rise in the incidence of GUD cases should be of some concern even though the 1998 percentage of 43.88 was still much lower than the $67 \%$ prevalence rate observed in 1990 by Kristernsen(3).

Furthermore, various researches have shown that non-ulcerative(12) and ulcerative STDs in particular(1316) increase the susceptibility to or transmissibility of HIV infection and as such, an increase in STD prevalence as revealed by clinic attendance in this study was bound to facilitate the spread of HIV/AIDS in Malawi. For example, Kristensen(3) in a previous study did confirm that $62.4 \%$ of 705 unselected patients at an STD clinic in Lilongwe Malawi were HIV sero-positive, while Mbizvo et al (17) and Fehler et al(18) working independently in Zimbabwe and South Africa respectively both obtained a $67 \%$ risk factor for contracting HIV among cohorts of STD patients.

One rather surprising observation made in this study was the possible influence of seasonal variation on STD clinic attendance which was consistently highest between March and May, peaking in April of each year (Figure 2). This might not be totally unconnected with Christmas and New year festivities during which time attendance at the STD clinic was lowest (Figure 2) because most people usually travel to their home towns and villages to celebrate Christmas while migrant workers reunite with their families and with most people in festive mood, sexual activities become heightened and the spread of STDs aggravated. The gradual increase in clinic attendance from January to April (Figure 2) perhaps validates this line of thought. In addition February/March period is usually the harvest time in Malawi(19) and with abundant food and money, sexual activities tend to increase. Furthermore Easter festivities too usually fall between March and April every year thus promoting more sexual activities and STD spread.

In conclusion, a $25 \%$ increase in attendance at the STD clinic, QECH, Blantyre, between 1991 and 1995(4) followed by a $30.7 \%$ increase between 1996 and 1998 as observed in this study cannot be good news to the health care delivery personnel in Malawi if these figures were to be regarded as indicators of the prevalence of STDs and possibly HIV infection in the country. Perhaps it is high time health planners adopted a more aggressive and resultoriented HIV/AIDS/STD awareness campaign strategy and if possible overhaul the approach to the way these campaigns are presently being passed across to the Malawian populace.

\section{ACKNOWLEDGEMENTS}

The co-operation and assistance of Mr Chilunga, Clinical Officer in charge of the STDs clinic, QECH, Blantyre is gratefully acknowledged.

\section{REFERENCES}

1. Keersmaekers K. and Meheus A. Epidemiology of sexually transmitted infections and AIDS in developing countries. In: Arya OP; Hart, C A. Eds sexually transmitted infections and AIDS in the tropics. Oxford: CAB International 1998: 3-30.

2. Lule, G.S., Moses, A. and Bandawe, C. Characteristics and sexual behaviour of individuals attending the sexually transmitted diseases clinic at Queen Elizabeth Central Hospital, Blantyre, Malawi Centr. Afr. J. Med . 1997; 43:16-11.

3. Kristensen J.K. The prevalence of symptomatic sexually transmitted diseases and human immunodeficiency virus in outpatients in Lilongwe, Malawi. Genitourin. Med. 1990; 66: 244-6.

4. Lule, G.S. and Ngwale, M. The effect of syndromic diagnosis on the attendances at a sexually transmitted disease clinic at $\mathrm{QECH}$, Blantyre. Trop. Hlth.

5. UNAIDS MALAWI. Vol I Issue I October 2, 1999: 1-2.

6. National AIDS Control Programme, Malawi. AIDS cases surveillance 1998 report. pp 1.

7. Schneider, H., Coetzee, D. J. and Fehler, H. G. et al. Screening for sexually transmitted diseases in rural South African women. Genitourin. Med. 1998: 74 (suppl): S147-S152.

8. Chikovore, J. and Mbizvo, M.T. AIDS related knowledge and sexual behaviour among commercial farm residents in Zimbabwe. Cent. Afr. J. Med. 1999; 45:7-10.

9. Faxelid, E., Ndulo, J., Ahlberg, B.M. and Krantz I. Behaviour, knowledge and reactions concerning sexually transmitted diseases: Implications for partner notification in Lusaka. East Afr. Med. J 1994; 71:118-121

10. Central Statistical Office. Zimbabwe Demographic and Health Survey, Harare, 1995.

11. Joint United Nations Programme on HIV/AIDS. Sexually transmitted diseases policies and principles for prevention and care 1997 pp 5-6.

12. Laga, M., Manika, A. and Kivuvu, M. et al. Non-ulcerative sexually transmitted diseases as risk factors for HIV-transmission in women: results from a cohort study. AIDS 1993; 3: 95-102.

13. Wasserheit, J.N. Epidemiological synergy: Interrelationships between human immunodeficiency virus infections and other sexually transmitted diseases. J STD 1992; 19:61-77.

14. Piot, P. and Tezzo, R. The epidemiology of HIV and other sexually transmitted infectious diseases in the developing world. Scand. J. Infect. Dis. 1990; 69:89-97.

15. Nsubuga, P., Mugerwa, R. and Nsibamb, J et al The association of genital ulcer disease and HIV infection at a dermatology - STD clinic in Uganda. AIDS 1990; 3:1002-5.

16. Greenblatt, R.M., Lukehart, S.A. and Plummer, F.A. et al.Genital ulceration as a risk factor for human immunodeficiency virus infection. AIDS 1998; 2: 47-60.

17. Mbizvo, M.T., Danso, A.P., Tswana S., Bassett, M., Marowa, and E., Moengeranwa. Reduced semen quality and risky behaviours amongst men consulting a referral STD clinic. Cent. Afr. J. Med. 1994; 40: 294-9.

18. Fehler, H.G., Lyall, M., Htun Ye, Muiznicks, S., Khoza, B.D. and Ballard, R.C. Genital tract infections among women attending an urban family planning clinic. South Afr. J. Epidem. Infect 1998; 13:79-81.

19. Nkekha, M., Kulmala, T., Vaahtera, M., Cullinan, T., Salin, M. and Ashorn, P. Seasonal variation in the dietary sources of energy for pregnant women in Lungwena, rural Malawi, Ecol. Food and Nutr. 2000; 38:605-622. 